\title{
Nucleostemin expression in invasive breast cancer
}

\author{
Takayuki Kobayashi ${ }^{1,2}$, Kenkichi Masutomi ${ }^{3}$, Kenji Tamura ${ }^{4}$, Tomoyuki Moriya ${ }^{5}$, Tamio Yamasaki ${ }^{5}$, Yasuhiro Fujiwara ${ }^{4}$, \\ Shunji Takahashi ${ }^{2}$, Junji Yamamoto ${ }^{5}$ and Hitoshi Tsuda ${ }^{1,6^{*}}$
}

\begin{abstract}
Background: Recently, the cancer stem cell hypothesis has become widely accepted. Cancer stem cells are thought to possess the ability to undergo self-renewal and differentiation, similar to normal stem cells. Nucleostemin (NS), initially cloned from rat neural stem cells, binds to various proteins, including p53, in the nucleus and is thought to be a key molecule for stemness. NS is expressed in various types of cancers; therefore, its role in cancer pathogenesis is thought to be important. This study was conducted to clarify the clinicopathological and prognostic impact of NS in invasive breast cancers.

Method: The correlation between NS immunoreactivity and clinicopathological parameters was examined in 220 consecutive surgically resected invasive breast cancer tissue samples by using tissue microarrays. The presence of nuclear NS and p53 immunoreactivity in 10\% or more of cancer cells was considered as a positive result.

Results: Among the 220 patients, 154 were hormone-receptor (HR)-positive, 22 HER2-positive/HR-negative, and 44 HR-negative/HER2-negative. One hundred and forty-two tumors (64.5\%) showed NS positivity, and this positivity was significantly correlated with estrogen receptor (ER) $(P=0.050)$, human epidermal growth factor receptor 2 (HER2) $(P=0.021)$, and p53 $(P=0.031)$ positivity. The patients with NS-positive tumors showed significantly shorter disease-free survival than those with NS-negative tumors. Furthermore, the patient group with NS- and p53-positive tumors showed significantly poorer prognosis than other patient groups. Multivariate analysis showed that NS status was an independent prognostic indicator.
\end{abstract}

Conclusions: NS may play a significant role in the determination of breast cancer progression in association with p53 alterations. The NS status of patients with luminal and HER2 type breast cancers may be a useful prognostic marker.

\section{Background}

Breast cancer is one of the most prevalent diseases worldwide. While most patients with early breast cancers are cured with surgically resection followed by appropriate adjuvant drug and radiation therapy, approximately $30 \%$ of these patients experience relapse and develop metastatic disease [1]. In this metastatic stage, tumor cells frequently acquire resistance to various drugs during intensive systemic therapies, and eventually their aggressiveness and growth become uncontrollable. Less than $5 \%$ of patients with distant metastatic tumors live for 5 years [2].

\footnotetext{
*Correspondence: htsuda@ndmc.ac.jp

'Department of Basic Pathology, National Defense Medical College, 3-2

Namiki, Tokorozawa, Saitama 359-8513, Japan

${ }^{6}$ Department of Pathology and Clinical Laboratories, National Cancer Center Hospital, 5-1-1 Tsukiji, Chuo-ku, Tokyo 104-0045, Japan

Full list of author information is available at the end of the article
}

Therefore, identification of potential targets with the aim of developing interventional drugs is an important area of research.

The hypothesis that various types of cancers, including breast cancer, are generated by a limited number of cancer stem cells has been widely accepted recently [3]. Cancer stem cells, like normal stem cells, are thought to have two important characteristics: the ability to undergo selfrenewal and the ability to undergo differentiation into different cell types [4]. Furthermore, these cells are thought to be inherently resistant to various therapeutic drugs, making the eradication of tumors containing cancer stem cells with the use of the current treatment protocols difficult [5]. To overcome these obstacles, the development of new therapeutic strategies to target cancer stem cells is essential for the management of breast cancer.

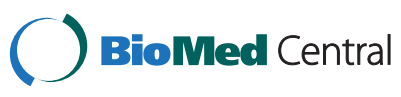


Nucleostemin (NS) is thought to be a key molecule for maintaining "stemness" [6]. NS was initially cloned from rat neural stem cells and was found to contain two GTP-binding motifs and an N-terminal basic domain, which is essential for binding to p53 [6]. NS accumulates mainly in the nucleoli and moves to the nucleoplasm after binding with GTP. Interaction of NS with a multitude of proteins in the nucleoplasm, including p53, may play a significant role in self-renewal, cell cycle regulation, apoptosis, and cell proliferation [7].

NS is expressed in central nervous system stem cells, embryonic stem cells, and primitive cells in the bone marrow and testes [6]. Furthermore, various types of cancers, including the following, have been reported to express NS: squamous cell carcinomas of the uterine cervix; head, neck, esophagus, and renal cell carcinomas; and prostate cancer [8-13]. Moreover, recent evidence indicates that NS is involved in maintaining cancer stem cells $[14,15]$. These findings suggest that NS may also play an important role in cancer pathogenesis as well as in cancer stem cell maintenance. However, no clinical study has investigated the role of NS in breast cancer.

If NS is expressed in breast cancer stem cells and its expression is correlated with disease progression in breast cancer, it may serve as a powerful prognostic marker for clinical use. To test this hypothesis, we investigated the expression of NS in surgically resected invasive breast cancer specimens from 220 patients by using immunohistochemistry. Furthermore, we examined the prognostic implication of the combination status of NS and p53 and the significance of NS expression status among the three biological subtypes of breast tumors: (a) hormone-receptor (HR) positive (luminal type); (b) human epidermal growth factor receptor 2 (HER2) positive (HER2 type); and (c) HR negative and HER2 negative (triple negative).

\section{Methods}

\section{Patients and tumor specimens}

The patient cohort used in the present study was the same as the cohort reported in our previous study [16]. Briefly, formalin-fixed paraffin-embedded tissue blocks of invasive breast cancer specimens from 220 consecutive patients were used to construct tissue microarrays (TMAs). All patients with unilateral invasive breast carcinoma underwent mastectomy or breast-conserving surgery at the National Defense Medical College (NDMC) Hospital, Tokorozawa, Japan from 1995 through 1999. These patients had a median follow-up of 74 months after surgery (range, 1-151 months), during which 58 patients experienced relapse. Of the 220 patients, 218 were female patients and 2 were male patients; 101 (45.9\%) patients had lymph node metastasis and 8 (3.6\%) had distant metastasis at the time of breast cancer diagnosis. In most cases, patients with hormone receptor-positive tumors at the time of diagnosis were prescribed adjuvant endocrine therapy (e.g., tamoxifen, toremifene, fadrozole, or LHRH analogues) for two or more years. The patients with a large tumor and/or four or more lymph node metastases received one of the following adjuvant chemotherapy regimens: cyclophosphamide-epirubicin-5-fluorouracil (CEF), cyclophosphamide-adriamycin-5-fluorouracil (CAF), cyclophosphamide-methotrexate-5-fluorouracil (CMF), and oral fluoropyrimidines. Detailed patient and disease characteristics are documented in Table 1. Clinicopathological data were retrospectively obtained from medical records [16].

This study was approved by the Medical Ethical Committee of National Defense Medical College and by the Institutional Review Board of National Cancer Center.

\section{Tissue microarray construction}

We constructed TMA blocks as previously described [16]. Briefly, double tissue cores with a diameter of $2 \mathrm{~mm}$ were obtained from each donor block, and these core specimens were transferred to a recipient block using a Tissue Microarrayer (Beecher Instruments, Silver Spring, MD, USA). One TMA block contained a maximum of 26 tumor samples, and 13 TMA sets were used in this study.

\section{Immunohistochemistry}

Immunohistochemistry was performed on TMA sections of 220 patients. The antibodies used were mouse monoclonal anti-human NS (clone BL2858; Bethyl Laboratories, Inc., Montgomery, TX, USA) and mouse monoclonal anti-human p53 (clone DO-7; Dako, Carpinteria, CA, USA). Formalin-fixed paraffin-embedded specimens on the TMA were cut into $4 \mu \mathrm{m}$-thick sections. The tissue sections were deparaffinized twice in xylene for $10 \mathrm{~min}$ and rehydrated through graded ethanol (99\%, 90\%, 80\%, and $70 \%)$ to water. Antigens were retrieved by microwave heating for $30 \mathrm{~min}$ in $10 \mathrm{mM}$ sodium citrate $(\mathrm{pH}$ 6.0) for $\mathrm{NS}$ and by autoclaving for $15 \mathrm{~min}$ in $10 \mathrm{mM}$ Tris- $\mathrm{HCl}$ ( $\mathrm{pH}$ 9.0) for $\mathrm{p} 53$. To block endogenous peroxidase activity, the sections were treated with $100 \%$ methanol containing 3\% hydrogen peroxide for 5 min. Non-specific binding was blocked by incubation in $2 \%$ normal swine serum (Dako) in phosphate-buffered saline. The slides were incubated with primary antibodies at $4^{\circ} \mathrm{C}$ overnight and then reacted with a dextran polymer reagent combined with secondary antibodies and peroxidase (Envision Plus; Dako) for $30 \mathrm{~min}$ at room temperature. Specific antigen-antibody reactions were visualized with $0.2 \%$ diaminobenzidine tetrahydrochloride and hydrogen peroxide. Counterstaining was performed using Mayer's hematoxylin. A separate assay was run using a case of esophageal carcinoma as a positive control for NS [17]. Reactions without the primary antibodies were used as negative controls. 
Table 1 Correlation between nucleostemin expression and clinicopathological variables in surgically resected breast cancers

\begin{tabular}{|c|c|c|c|c|}
\hline \multirow[t]{4}{*}{ Variable } & \multirow[b]{3}{*}{ Total } & \multirow{2}{*}{\multicolumn{3}{|c|}{$\begin{array}{c}\text { Number of cases (\%) } \\
\text { Nucleostemin expression }\end{array}$}} \\
\hline & & & & \\
\hline & & \multirow{2}{*}{$\frac{\text { Positive }}{(n=142)}$} & \multirow{2}{*}{$\frac{\text { Negative }}{(n=78)}$} & \multirow[t]{2}{*}{ P-value } \\
\hline & $(n=220)$ & & & \\
\hline \multicolumn{5}{|l|}{ Age } \\
\hline Median (range) & \multicolumn{4}{|c|}{$52(30 \sim 82$ y) } \\
\hline$\leqq 52$ & 109 & $71(65)$ & 38 & 0.89 \\
\hline$>52$ & 111 & $71(64)$ & 40 & \\
\hline \multicolumn{5}{|l|}{ Tumor size } \\
\hline$<5.0 \mathrm{~cm}$ & 174 & $108(62)$ & 66 & 0.21 \\
\hline$\geqq 5.0 \mathrm{~cm}$ & 42 & $31(74)$ & 11 & \\
\hline Unknown & 4 & $4(100)$ & 0 & \\
\hline \multicolumn{5}{|c|}{ Lymph node metastasis } \\
\hline Negative & 115 & $70(61)$ & 45 & 0.39 \\
\hline Positive & 101 & $68(67)$ & 33 & \\
\hline Unknown & 4 & $4(100)$ & 0 & \\
\hline \multicolumn{5}{|l|}{ Distant metastasis } \\
\hline Negative & 209 & $134(64)$ & 75 & 0.72 \\
\hline Positive & 8 & $6(75)$ & 2 & \\
\hline Unknown & 3 & $2(67)$ & 1 & \\
\hline \multicolumn{5}{|l|}{ Stage } \\
\hline | or || & 179 & $111(61)$ & 68 & 0.13 \\
\hline III or IV & 37 & $28(76)$ & 9 & \\
\hline Unknown & 4 & $3(75)$ & 1 & \\
\hline \multicolumn{5}{|l|}{ Nuclear grade } \\
\hline 1,2 & 137 & $86(63)$ & 51 & 0.48 \\
\hline 3 & 83 & $56(67)$ & 27 & \\
\hline \multicolumn{5}{|l|}{ ER status } \\
\hline Negative & 88 & $50(57)$ & 38 & 0.050 \\
\hline Positive & 132 & $92(70)$ & 40 & \\
\hline \multicolumn{5}{|l|}{ PgR status } \\
\hline Negative & 96 & $57(59)$ & 39 & 0.16 \\
\hline Positive & 124 & $85(69)$ & 39 & \\
\hline \multicolumn{5}{|l|}{ HR (ER/PgR) status } \\
\hline Negative & 66 & $40(61)$ & 26 & 0.42 \\
\hline Positive & 154 & $102(66)$ & 52 & \\
\hline \multicolumn{5}{|l|}{ HER2 status } \\
\hline Negative & 190 & $117(62)$ & 73 & 0.02 \\
\hline Positive & 30 & $25(83)$ & 5 & \\
\hline \multicolumn{5}{|l|}{ p53 status } \\
\hline Negative & 143 & $85(59)$ & 58 & 0.03 \\
\hline Positive & 77 & $57(74)$ & 20 & \\
\hline
\end{tabular}

Table 1 Correlation between nucleostemin expression and clinicopathological variables in surgically resected breast cancers (Continued)

\begin{tabular}{lcccc}
\hline Histological type & & & & \\
Ductal & 191 & $125(65)$ & 66 & 0.38 \\
Lobular & 10 & $5(50)$ & 5 & \\
Mucinous & 6 & $6(100)$ & 0 & \\
Tubular & 5 & $1(20)$ & 4 & \\
Medullary & 3 & $2(67)$ & 1 \\
Other & 5 & $3(60)$ & 2 \\
\hline
\end{tabular}

Abbreviation: ER Estrogen receptor, PgR Progesterone receptor, HR Hormone receptor.

NS and p53 expression was assessed according to the proportion of nuclear staining area. Specimens with $10 \%$ or more immunoreactive tumor cells were considered positive, and those with less than $10 \%$ were considered negative. Immunohistochemistry results were independently evaluated by two observers (T.K. and H.T.), and cases with discrepant grades were re-evaluated by discussion until consensus was achieved.

ER, PgR, and HER2 had already been immunohistochemically re-assessed on new sections in our previous study [16] by using mouse monoclonal anti-human ER (clone 1D5, Dako), mouse anti-human PgR (clone PgR636, DAKO), and rabbit polyclonal anti-HER2 antibody (HercepTest kit, Dako) according to the methods recommended by the manufacturer. ER and PgR were considered positive if the nuclear staining was observed in $10 \%$ or more of tumor cells. Samples were considered hormone receptor positive if they were ER and/or PgR positive and hormone receptor negative if they were ER and PgR negative. HER2 results were considered positive if the IHC score was " $3+$ " or gene amplification was detected by FISH according to the 2007 ASCO/CAP guideline [18].

\section{Statistical analysis}

Comparisons between groups were evaluated using chisquared test or Fisher's exact test. Disease-free survival (DFS) curves of patients were drawn using the Kaplan-Meier method and compared using the log-rank test. Cox multivariate proportional hazards models were used to explore the association of variables with DFS. For all tests, $P<0.05$ was considered to be statistically significant. All analyses were performed using the software JMP 6.0 for Windows (SAS Institute Inc., Cary, NC, USA).

\section{Results}

Clinicopathological and prognostic implications of NS expression for the entire patient cohort

Initially, the expression levels of NS were classified as negative $(0 \%)$, weak ( $1 \%$ to $<10 \%)$, moderate $(10 \%$ to $<30 \%)$, or strong (30\% or more). The number of cases categorized 
into the negative, weak, moderate, and strong groups was $62,16,55$, and 87, respectively. From these results, we judged that NS expression showed bimodal distribution and used a $10 \%$ threshold for NS positivity between negative and positive groups.

NS protein was frequently detected in the nucleus of breast cancer cells. Although strong immunoreaction was observed in both the nucleoli and nucleoplasm of cancer cells (Figure 1A), nuclear immunoreaction of NS in some cases was limited to the nucleoli of cancer cells (Figure 1B). Such cells were also judged as positive for NS immunoreactivity. Cytoplasmic staining was not observed. These findings are consistent with those of previous reports $[6,17,19]$. We found that $78(35.5 \%)$ or 142 (64.5\%) patients had NS-negative or NS-positive tumors, respectively (Figure $1 \mathrm{C}$ ). Unremarkable mammary glands showed nuclear NS immunoreactivity in almost all luminal epithelial cells (Figure 1D).

Tumors with NS positivity showed a higher frequency of ER positivity, HER2 positivity, and p53 positivity $(P=0.050, P=0.021$, and $P=0.031$, respectively), whereas NS expression status was not correlated with tumor size, lymph node metastasis, distant metastasis, tumor nuclear grade, or PgR positivity. NS expression was detected at $50 \%$ or more in all histological types studied except tubular carcinoma (20\%), and the positive rate was $100 \%$ (6 of 6 ) in mucinous carcinoma. Patients with NS-positive tumors showed significantly shorter DFS time than those with NS-negative tumors $(P=0.020$, Figure 2).

\section{Prognostic implication of the NS and p53 combination status for the entire patient cohort}

Since it has been reported that physical and functional interaction between NS and p53 appear to be essential for self-renewal, cell cycle regulation, cell proliferation, and apoptosis [7], we next examined the prognostic implication of the combination status of NS and p53 for the entire patient cohort. We found that 143 (65\%) and 77 (35\%) patients had p53-negative and p53-positive tumors, respectively. The patients with p53-positive tumors showed significantly shorter DFS time than those with p53-negative tumors $(P=0.006$, Figure $3 \mathrm{~A})$.

A striking stratification of relapse risk was identified when three different combinations of NS and p53 status were evaluated: 57 cases with a combination of NS-positive/p53-positive tumors (unfavorable group); 105 cases comprising 20 NS-negative/p53-positive tumors and 85 NS-positive/p53-negative tumors (intermediate group); and 58 cases with NS-negative/p53-negative tumors (favorable group). The unfavorable group had a 5-year DFS rate of $55 \%$, compared with $75 \%$ in the intermediate group and $86 \%$ in the favorable group (Figure $3 \mathrm{~B}$ ). The unfavorable group had significantly shorter DFS time than the intermediate and favorable groups (log-rank test $P=0.034$ and $P=0.0007$, respectively).
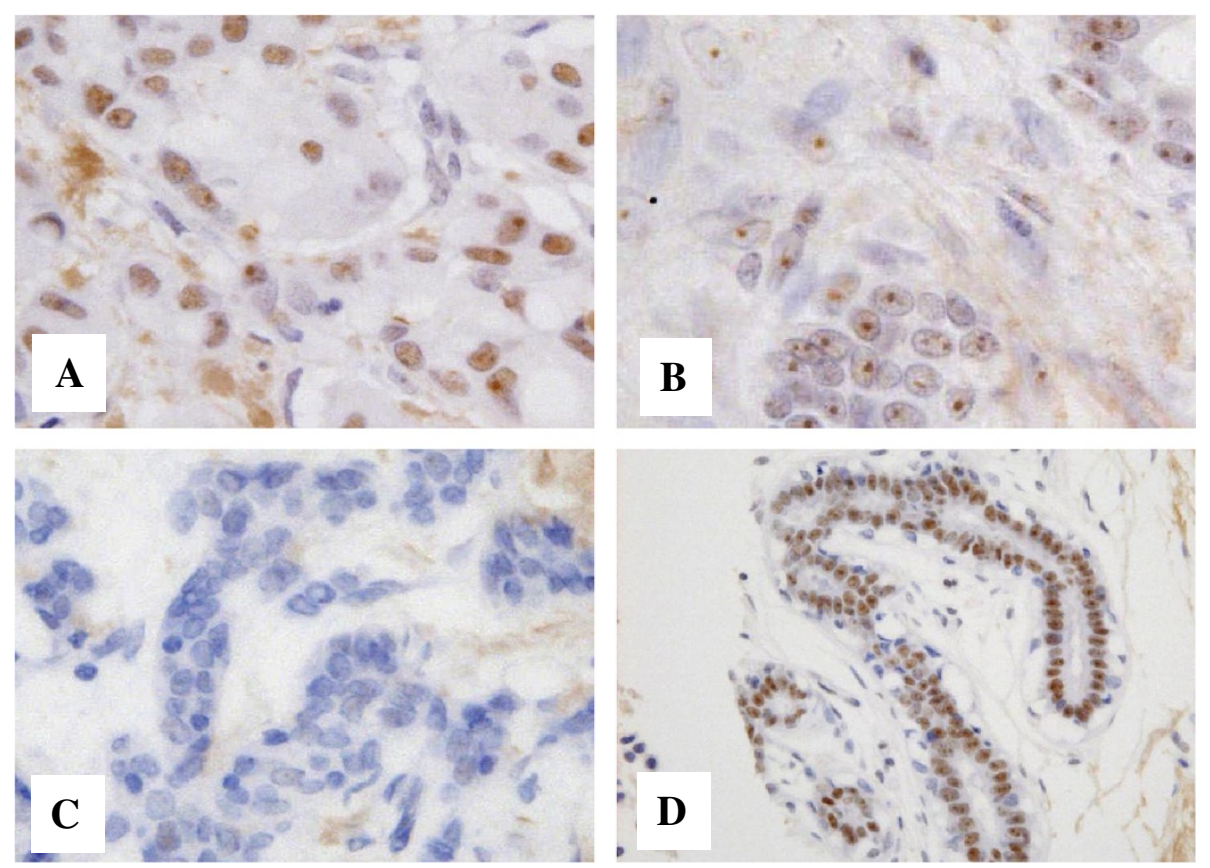

Figure 1 Nucleostemin (NS) expression in human breast cancer tissues. A. A NS-positive tumor. Almost all cancer cells show NS immunoreactivity in both nucleoli and nucleoplasm. B. Another NS-positive tumor, NS immunoreactivity is limited to nucleoli in nuclei of cancer cells. Such cancer cells are also judged as NS-positive. This case was also classified as NS-positive. C. A NS-negative tumor. D. An unremarkable mammary gland shows nuclear NS immunoreactivity in almost all luminal epithelial cells. 


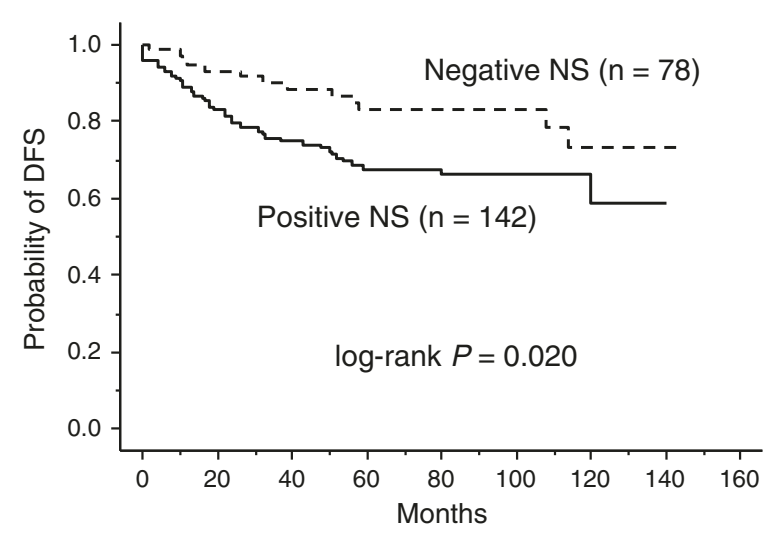

Figure 2 Prognostic impact of NS status in the patients with primary breast cancer. This figure shows disease-free survival (DFS) curves for the 142 patients with NS-positive tumors and for the 78 patients with NS-negative tumors. These two curves differ significantly $(P=0.020)$.

\section{Prognostic implication of NS among the three biological subtypes of breast tumors}

Currently, treatment strategies differ between the biological subtypes of breast tumors; therefore, we examined the prognostic implication of NS among three groups of patients divided based on their biological subtype: 154 patients with luminal-type tumors (HR-positive); 22 patients with HER2-type tumors (HER2-positive and HR-negative); and 44 patients with triple-negative tumors (HR and HER2-negative). Eight patients with HR-positive and HER2-positive tumors were included and analyzed as luminal-type patients.

Among the patients with luminal-type tumors, patients with NS-positive tumors showed a significantly shorter DFS time than those with NS-negative tumors $(P=0.033$, Figure $4 \mathrm{~A})$. Among the patients with HER2positive tumors, patients with NS-positive tumors had a 5 -year DFS rate of $28 \%$ compared with $100 \%$ in patients with NS-negative tumors (Figure 4B). However, the $P$-value was not calculated because there was no relapse
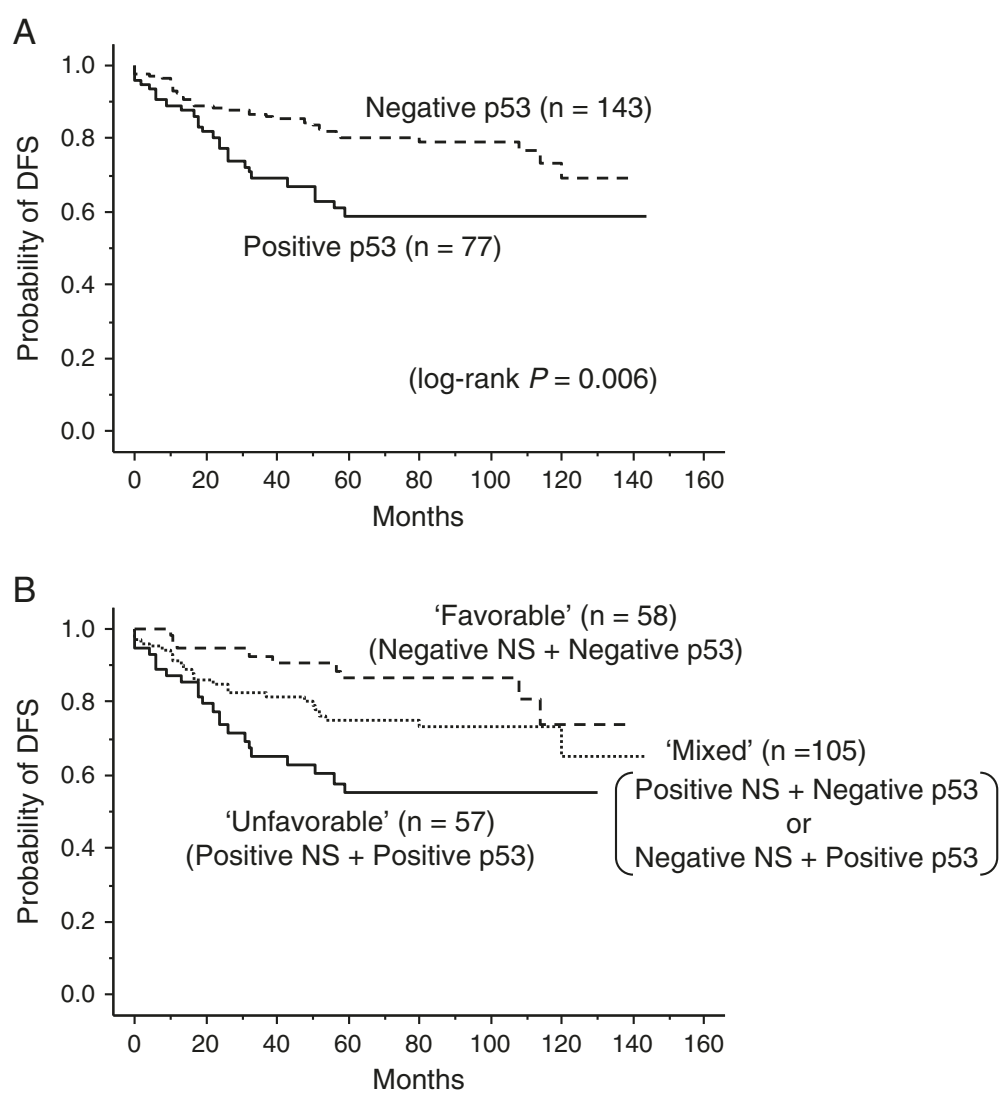

Figure 3 Prognostic impact of the combination status of NS and p53 in the patients with primary breast cancer. A. Disease-free survival (DFS) curves for the 77 patients with p53-positive tumors and for the 143 patients with p53-negative tumors. These two curves differ significantly $(P=0.006)$. B. This figure shows three disease-free survival (DFS) curves: for the 57 patients with NS-positive and p53-positive tumors ('unfavorable group'), for 105 patients comprising 20 NS-negative and p53-positive tumors and 85 NS-positive and p53-negative tumors ('intermediate' group), and for 58 patients with NS-negative and p53-negative tumors ('favorable' group). The unfavorable group has significantly shorter DFS time than the intermediate group or the favorable group (log-rank test $P=0.034$ and $P=0.0007$, respectively). 




Figure 4 Prognostic impact of NS status in the three subgroups of the different biological subtype tumors: luminal-type tumors, HER2-type tumors, and triple-negative tumors.

A. Subgroup analysis of the 154 patients with luminal-type tumors (HR-positive tumors). Two disease-free survival (DFS) curves, that for the 102 patients with NS-positive tumors and that for the 52 patients with NS negative tumors, differ significantly $(P=0.033)$. B. Subgroup analysis of the 22 patients with HER2-type tumors (HER2-positive and HR-negative tumors). In two disease-free survival (DFS) curves, that for the 18 patients with NS-positive tumors and that for the 4 patients with NS-negative tumors, five-year DFS rates differ largely (100\% vs $28 \%)$. $P$-value was not available because there was no relapse in the patients with NS-negative tumors. C. Subgroup analysis of the 44 patients with triple-negative tumors (HR and HER2 negative tumors). The two curves do not differ significantly $(P=0.41)$.

in the four patients with NS-negative tumors. Among the patients with triple-negative tumors, there was no difference between the survival curves for patients with NS-positive tumors and those with NS-negative tumors $(P=0.41$, Figure $4 \mathrm{C})$.

\section{Multivariate analysis of prognostic factors and evaluation of NS}

Univariate analysis showed that HR, HER2, nuclear grade, tumor size, nodal status, distant metastasis, and NS expression were significantly correlated with DFS. When multivariate analysis was performed using these seven factors, NS expression status was selected as an independent prognostic factor $(P=0.036)$, together with nuclear grade, tumor size, lymph node status, and distant metastatic status $(P=0.0008,0.0007,0.0038$ and $<0.0001$, respectively; Table 2).

\section{Discussion}

In the present cohort, we found that the NS protein expression status was positively correlated with both ER and HER2 status and was a powerful prognostic factor. Patients with NS-positive breast tumors had a significantly shorter DFS time than those with NS-negative tumors $(P=0.020$, Figure 2$)$, and multivariate analysis for DFS showed that NS positivity had an independent impact as a prognostic indicator among breast cancer patients $(P=0.036$, Table 2$)$. To our knowledge, this is the first report to show the clinical implication of NS protein expression in invasive breast cancers.

Although several studies have shown the important roles of NS in the pathogenesis of various cancer types [8-13] as well as the maintenance of cancer stem cells $[14,15]$, no direct evidence is yet available to support that NS is a marker of cancer stem cells. Currently, molecules such as CD44, CD133, ALDH1, and CXCR4 have been found to be potential markers of cancer stem cells [20-25]. Furthermore, the expression of these stem cell markers has been shown to be a poor prognostic 
Table 2 Prognostic impacts of clinicopathological variables computed by Cox's univariate and multivariate analyses in patients with primary breast cancer

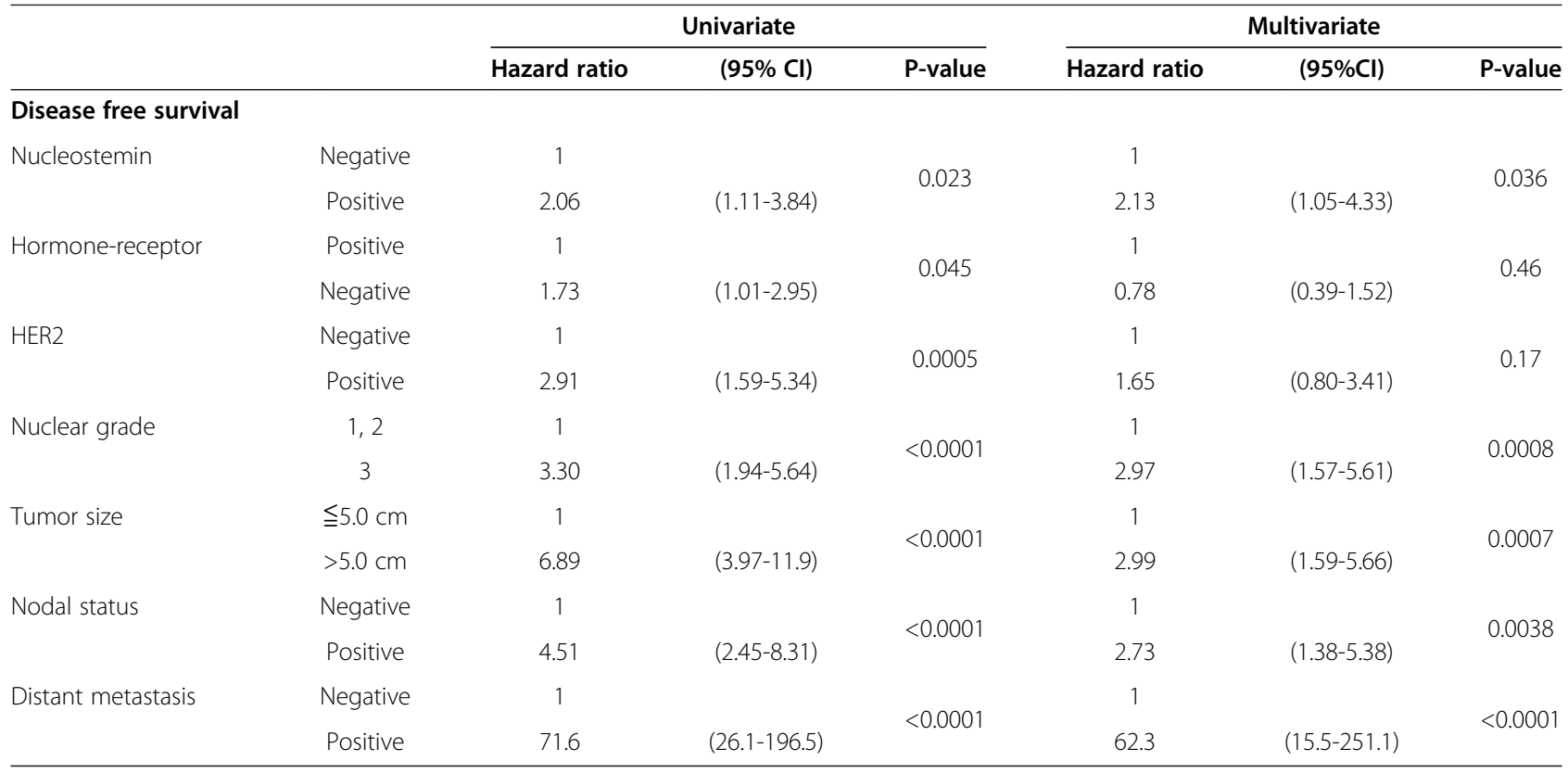

indicator in several human cancer types [24,26-30]. Based on these observations, our results show that high NS expression is a powerful indicator of poor outcome, consistent with the idea that NS may be a breast cancer stem cell marker.

The limitations of the present study included the retrospective analyses and the heterogeneity of adjuvant treatments. Therefore, one should pay careful attention when interpreting these results. Further studies using a uniformly treated patient cohort are required to clarify the role of NS in breast cancer stem cells.

We found that the patient group with tumors coexpressing NS and p53 had shorter DFS times than the patient group with tumors negative for either NS or p53. GTP binding modulates the movement of NS from the nucleoli to the nucleoplasm; NS then binds p53 at its $\mathrm{N}$-terminal basic domain, which results in the suppression of p53 function [6,7]. Because prolongation of the half-life of most of the mutated p53 protein induces its nuclear accumulation, it is generally believed that the p53 pathway does not fully function in tumors with high p53 nuclear immunoreactivity [31-33]. This evidence leads to the assumption that p53 function would be profoundly suppressed in tumors coexpressing NS and p53. Our results show the validity of this concept and that functional crosstalk between NS and p53 may also occur in vivo.

Currently, we cannot explain the correlation between NS expression and p53 expression. Although several studies have shown that NS modulates the expression of wild-type p53 [34,35], the role of NS in breast cancers with mutant p53 has not yet been evaluated. Further research is needed to elucidate the correlation.

We found that the NS expression status was positively correlated with both ER and HER2 status and also found a significant prognostic implication of NS expression for patients with luminal-type tumors and those with HER2-type tumors, except for those with triple-negative tumors. NS was first identified as a gene upregulated in MCF-7 cells upon 17 $\beta$-estradiol treatment [36]; therefore, our inclusion of subgroup analysis among patients with luminal-type tumors was reasonable. To our knowledge, this is the first report to demonstrate the possible association between NS and HER2. Zhang G et al. showed that NS is required for the expression of EGF and EGFR in an esophageal squamous carcinoma cell line [13]. Presumably, NS is required for the expression of HER2 in a manner similar to that for EGFR. We found no survival impact of the NS expression status among patients with triple-negative tumors, who show higher rates of mutated p53 than patients with luminaltype or HER2-type tumors [37]. NS can function in the presence of wide-type p53 [7]; therefore, the expression status of NS may have survival impact only for the luminal-type and HER2-type tumors.

\section{Conclusions}

In summary, our results indicate that the expression status of NS, abundant in stem cells, is a prognostic indicator in breast cancer patients, especially for those with 
luminal-type or HER2-type tumors, and that the coexpression of NS and p53 correlates with poorer prognostic outcomes. Examination of NS expression may be useful for the stratification and management of breast cancer patients in future daily practice.

\section{Competing interests}

The authors declare no conflicts of interest.

\section{Authors' contributions}

TK and HT conceived of the study, performed experiments, analyzed data and wrote the manuscript. $T M, T Y$, and JY provided samples, collected clinical and pathological data. KM, KT, YF, and ST participated in designing the study and revising the manuscript. HT participated in the overall design and study coordination and finalized the draft of the manuscript. All authors read and approved the final manuscript.

\section{Acknowledgments}

This work was supported in part by the Foundation for Promotion of Defense Medicine and by the Cancer Research and Development Fund from the National Cancer Center, Japan.

\section{Author details}

'Department of Basic Pathology, National Defense Medical College, 3-2 Namiki, Tokorozawa, Saitama 359-8513, Japan. ${ }^{2}$ Department of Medical Oncology, Cancer Institute Hospital, 3-8-31 Ariake, Koto-ku, Tokyo 135-8550, Japan. ${ }^{3}$ Division of Cancer Stem Cell, National Cancer Center Research Institute, Tsukiji, Chuo-ku, Tokyo 104-0045, Japan. ${ }^{4}$ Department of Breast Oncology and Medical Oncology, National Cancer Center Hospital, 5-1-1 Tsukiji, Chuo-ku, Tokyo 104-0045, Japan. ${ }^{5}$ Department of Surgery, National Defense Medical College, 3-2 Namiki, Tokorozawa, Saitama 359-8513, Japan. ${ }^{6}$ Department of Pathology and Clinical Laboratories, National Cancer Center Hospital, 5-1-1 Tsukiji, Chuo-ku, Tokyo 104-0045, Japan.

Received: 19 October 2013 Accepted: 11 March 2014

Published: 21 March 2014

\section{References}

1. O'Shaughnessy J: Extending survival with chemotherapy in metastatic breast cancer. Oncologist 2005, 10(Suppl 3):20-29.

2. Pagani O, Senkus E, Wood W, Colleoni M, Cufer T, Kyriakides S, Costa A, Winer EP, Cardoso F: International guidelines for management of metastatic breast cancer: can metastatic breast cancer be cured? J Natl Cancer Inst 2010, 102(7):456-463.

3. Clarke MF, Fuller M: Stem cells and cancer: two faces of eve. Cell 2006, 124(6):1111-1115.

4. Reya T, Morrison SJ, Clarke MF, Weissman IL: Stem cells, cancer, and cancer stem cells. Nature 2001, 414(6859):105-111.

5. Dean M, Fojo T, Bates S: Tumour stem cells and drug resistance. Nat Rev Cancer 2005, 5(4):275-284.

6. Tsai RY, McKay RD: A nucleolar mechanism controlling cell proliferation in stem cells and cancer cells. Genes Dev 2002, 16(23):2991-3003.

7. Bernardi R, Pandolfi PP: The nucleolus: at the stem of immortality. Nat Med 2003, 9(1):24-25.

8. Ye F, Zhou C, Cheng Q, Shen J, Chen H: Stem-cell-abundant proteins Nanog, Nucleostemin and Musashi1 are highly expressed in malignant cervical epithelial cells. BMC Cancer 2008, 8:108.

9. Fan Y, Liu Z, Zhao S, Lou F, Nilsson S, Ekman P, Xu D, Fang X: Nucleostemin mRNA is expressed in both normal and malignant renal tissues. Br J Cancer 2006, 94(11):1658-1662.

10. Liu RL, Zhang ZH, Zhao WM, Wang M, Qi SY, Li J, Zhang Y, Li SZ, Xu Y: Expression of nucleostemin in prostate cancer and its effect on the proliferation of PC-3 cells. Chin Med J (Engl) 2008, 121(4):299-304.

11. Cada Z, Boucek J, Dvorankova B, Chovanec M, Plzak J, Kodets R, Betka J, Pinot GL, Gabius HJ, Smetana K Jr: Nucleostemin expression in squamous cell carcinoma of the head and neck. Anticancer Res 2007, 27(5A):3279-3284.

12. Malakootian M, Mowla SJ, Saberi H, Asadi MH, Atlasi Y, Shafaroudi AM: Differential expression of nucleostemin, a stem cell marker, and its variants in different types of brain tumors. Mol Carcinog 2010, 49(9):818-825.
13. Zhang G, Zhang Q, Yin L, Li S, Cheng K, Zhang Y, Xu H, Wu W: Expression of nucleostemin, epidermal growth factor and epidermal growth factor receptor in human esophageal squamous cell carcinoma tissues. J Cancer Res Clin Oncol 2010, 136(4):587-594.

14. Tamase A, Muraguchi T, Naka K, Tanaka S, Kinoshita M, Hoshii T, Ohmura M, Shugo H, Ooshio T, Nakada M, Sawamoto K, Onodera M, Matsumoto K, Oshima M, Asano M, Saya H, Okano H, Suda T, Hamada J, Hirao A: Identification of tumor-initiating cells in a highly aggressive brain tumor using promoter activity of nucleostemin. Proc Natl Acad Sci U S A 2009, 106(40):17163-17168.

15. Okamoto N, Yasukawa M, Nguyen C, Kasim V, Maida Y, Possemato R, Shibata T, Ligon KL, Fukami K, Hahn WC, Masutomi K: Maintenance of tumor initiating cells of defined genetic composition by nucleostemin. Proc Natl Acad Sci U S A 2011, 108(51):20388-20393.

16. Kobayashi T, Tsuda H, Moriya T, Yamasaki T, Kikuchi R, Ueda S, Omata J, Yamamoto J, Matsubara O: Expression pattern of stromal cell-derived factor-1 chemokine in invasive breast cancer is correlated with estrogen receptor status and patient prognosis. Breast Cancer Res Treat 2010, 123(3):733-745.

17. Nakajima TE, Yoshida H, Okamoto N, Nagashima K, Taniguchi H, Yamada Y, Shimoda T, Masutomi K: Nucleostemin and TWIST as predictive markers for recurrence after neoadjuvant chemotherapy for esophageal carcinoma. Cancer Sci 2012, 103(2):233-238.

18. Wolff AC, Hammond ME, Schwartz JN, Hagerty KL, Allred DC, Cote RJ, Dowsett M, Fitzgibbons PL, Hanna WM, Langer A, McShane LM, Paik S, Pegram MD, Perez EA, Press MF, Rhodes A, Sturgeon C, Taube SE, Tubbs R, Vance GH, van de Vijver M, Wheeler TM, Hayes DF: American Society of Clinical Oncology/College of American Pathologists guideline recommendations for human epidermal growth factor receptor 2 testing in breast cancer. J Clin Oncol 2007, 25(1):118-145.

19. Yoshida R, Fujimoto T, Kudoh S, Nagata M, Nakayama H, Shinohara M, Ito T: Nucleostemin affects the proliferation but not differentiation of oral squamous cell carcinoma cells. Cancer Sci 2011, 102(7):1418-1423.

20. Al-Hajj M, Wicha MS, Benito-Hernandez A, Morrison SJ, Clarke MF: Prospective identification of tumorigenic breast cancer cells. Proc Natl Acad Sci U S A 2003, 100(7):3983-3988.

21. O'Brien CA, Pollett A, Gallinger S, Dick JE: A human colon cancer cell capable of initiating tumour growth in immunodeficient mice. Nature 2007, 445(7123):106-110.

22. Ricci-Vitiani L, Lombardi DG, Pilozzi E, Biffoni M, Todaro M, Peschle C, De Maria R: Identification and expansion of human colon-cancer-initiating cells. Nature 2007, 445(7123):111-115.

23. Singh SK, Hawkins C, Clarke ID, Squire JA, Bayani J, Hide T, Henkelman RM, Cusimano MD, Dirks PB: Identification of human brain tumour initiating cells. Nature 2004, 432(7015):396-401.

24. Ginestier C, Hur MH, Charafe-Jauffret E, Monville F, Dutcher J, Brown M, Jacquemier J, Viens P, Kleer CG, Liu S, Schott A, Hayes D, Birnbaum D, Wicha MS, Dontu G: ALDH1 is a marker of normal and malignant human mammary stem cells and a predictor of poor clinical outcome. Cell Stem Cell 2007, 1(5):555-567.

25. Hermann PC, Huber SL, Herrler T, Aicher A, Ellwart JW, Guba M, Bruns CJ, Heeschen C: Distinct populations of cancer stem cells determine tumor growth and metastatic activity in human pancreatic cancer. Cell Stem Cell 2007, 1(3):313-323.

26. Joensuu H, Klemi PJ, Toikkanen S, Jalkanen S: Glycoprotein CD44 expression and its association with survival in breast cancer. Am J Pathol 1993, 143(3):867-874.

27. Tempfer C, Losch A, Heinzl H, Hausler G, Hanzal E, Kolbl H, Breitenecker G, Kainz C: Prognostic value of immunohistochemically detected CD44 isoforms CD44v5, CD44v6 and CD44v7-8 in human breast cancer. Eur J Cancer 1996, 32A(11):2023-2025.

28. Horst D, Kriegl L, Engel J, Kirchner T, Jung A: CD133 expression is an independent prognostic marker for low survival in colorectal cancer. Br J Cancer 2008, 99(8):1285-1289.

29. Maeda S, Shinchi H, Kurahara H, Mataki Y, Maemura K, Sato M, Natsugoe S, Aikou T, Takao S: CD133 expression is correlated with lymph node metastasis and vascular endothelial growth factor-C expression in pancreatic cancer. Br J Cancer 2008, 98(8):1389-1397.

30. Marechal R, Demetter P, Nagy N, Berton A, Decaestecker C, Polus M, Closset J, Deviere J, Salmon I, Van Laethem JL: High expression of CXCR4 may predict poor survival in resected pancreatic adenocarcinoma. $\mathrm{Br} J$ Cancer 2009, 100(9):1444-1451. 
31. Davidoff AM, Herndon JE 2nd, Glover NS, Kerns BJ, Pence JC, Iglehart JD, Marks JR: Relation between p53 overexpression and established prognostic factors in breast cancer. Surgery 1991, 110(2):259-264.

32. Bartek J, Bartkova J, Lukas J, Staskova Z, Vojtesek B, Lane DP: Immunohistochemical analysis of the p53 oncoprotein on paraffin sections using a series of novel monoclonal antibodies. J Pathol 1993, 169(1):27-34.

33. Soussi $T$, Legros $Y$, Lubin $R$, Ory $K$, Schlichtholz B: Multifactorial analysis of p53 alteration in human cancer: a review. Int J Cancer 1994, 57(1):1-9.

34. Ma H, Pederson T: Depletion of the nucleolar protein nucleostemin causes G1 cell cycle arrest via the p53 pathway. Mol Biol Cell 2007, 18(7):2630-2635.

35. Dai MS, Sun XX, Lu H: Aberrant expression of nucleostemin activates p53 and induces cell cycle arrest via inhibition of MDM2. Mol Cell Biol 2008, 28(13):4365-4376.

36. Charpentier AH, Bednarek AK, Daniel RL, Hawkins KA, Laflin KJ, Gaddis S, MacLeod MC, Aldaz CM: Effects of estrogen on global gene expression: identification of novel targets of estrogen action. Cancer Res 2000, 60(21):5977-5983.

37. Sorlie T, Perou CM, Tibshirani R, Aas T, Geisler S, Johnsen H, Hastie T, Eisen $M B$, van de Rijn M, Jeffrey SS, Thorsen T, Quist $H$, Matese JC, Brown PO, Botstein D, Eystein Lonning P, Borresen-Dale AL: Gene expression patterns of breast carcinomas distinguish tumor subclasses with clinical implications. Proc Natl Acad Sci U S A 2001, 98(19):10869-10874.

doi:10.1186/1471-2407-14-215

Cite this article as: Kobayashi et al:: Nucleostemin expression in invasive breast cancer. BMC Cancer 2014 14:215.

\section{Submit your next manuscript to BioMed Central and take full advantage of:}

- Convenient online submission

- Thorough peer review

- No space constraints or color figure charges

- Immediate publication on acceptance

- Inclusion in PubMed, CAS, Scopus and Google Scholar

- Research which is freely available for redistribution 